\title{
HUMAN CHORIONIC GONADOTROPIN (H.C.G.) IN SUPPRESSION OF PRETERM LABOUR
}

Prakriti Goswami ${ }^{1}$, Veena Agrawal ${ }^{2}$

\section{HOW TO CITE THIS ARTICLE:}

Prakriti Goswami, Veena Agrawal. "Human Chorionic Gonadotropin (H.C.G.) in Suppression of Preterm Labour". Journal of Evolution of Medical and Dental Sciences 2015; Vol. 4, Issue 49, June 18; Page: 8475-8482, DOI: $10.14260 /$ jemds/2015/1229

ABSTRACT: CONTEXT/BACKGROUND: Preterm birth refers to a birth that occurs before 37 completed weeks (<259 days) of gestation. Preterm labour is a major healthcare problem throughout the world. Various drug therapies have been tried to suppress preterm labour, most of which are associated with maternal \& fetal side effects. H.C.G., by virtue of its known ability to suppress contractions in human myometrial muscles in vitro \& safety in pregnancy, can be used to suppress preterm labour. AIMS: To evaluate the role of Human Chorionic Gonadotropin in suppression of preterm labour. SETTINGS \& DESIGN: Prospective study conducted in the Department of Obstetrics \& Gynaecology at Kamla Raja Hospital, Gwalior, M. P. from August 2011 to September 2012. SAMPLE SIZE: 50. METHODS \& MATERIALS: 50 patients having preterm contractions and labour, with intact membranes, cervical dilatation less than $3 \mathrm{~cm} \&$ effacement less than $80 \%$ were given H.C.G., firstly 5000 units intramuscularly followed by 10,000 unit of H.C.G. in $500 \mathrm{ml}$ of dextrose $5 \%$, at the rate of 20 drops per minute. Efficacy was determined by observing subsidence of uterine contractions \& tocolysis was considered successful when delivery was delayed by 48hrs, giving time for the administered corticosteroids to accelerate fetal lung maturation. STATISTICAL ANALYSIS: Was done using Microsoft Excel. RESULTS: Mean duration between initiation of treatment and suppression of contraction was $3.1 \pm 0.12 \mathrm{hrs}$. Average age of labour within $48 \mathrm{hrs}$ was $8 \%$ i.e. treatment failed in 4 out of 50 patients. Mean prolongation of pregnancy was 31.4 \pm 17.06 days. Prolongation of pregnancy was maximum in women with gestational age between 28-29 wks 6 days (40.75 \pm 17.4 days) and in women with preterm contractions having Bishop's score in range of 0-4 (38.1 days). Mean birth weight in our study was $2.35 \pm 0.62 \mathrm{kgs}, 62 \%$ of babies weighed between 1.5 to $2.5 \mathrm{kgs}$. No maternal and neonatal side effects were seen. CONCLUSION: H.C.G. exhibits potent tocolysis with no maternal \& neonatal side effects. Further studies need to be done to establish the role of H.C.G. in suppression of preterm labour.

KEYWORDS: H.C.G., Preterm labour, Tocolytic.

INTRODUCTION: American college of obstetrics \& gynaecology (ACOG) in 1995 has defined preterm labour as labours which take place after 20th week and before 37 th week of pregnancy. Preterm labour constitutes about $10 \%$ of total labours, but since $70 \%$ of infants mortality is due to this, this problem is considered as one of the international indices in assessment of health condition worldwide. (1)

Any preterm birth postponed by more than $48 \mathrm{hrs}$ helps to administer glucocorticoids to the mothers, for acceleration of fetal lung maturation and reduction of risks of neonatal intraventricular haemorrhage and necrotizing enterocolitis, thereby reducing neonatal morbidity and mortality. This also gives clinicians time to refer mothers to a higher centre possessing neonatal intensive care unit (NICU). Various treatments have been employed to suppress preterm labour by reducing uterine contractions. ${ }^{(1,2)}$ 


\section{ORIGINAL ARTICLE}

Human Chorionic Gonadotropin (H.C.G.) is a heterodimeric glycoprotein produced primarily in the placenta and has multiple endocrine, paracrine and immunoregulatory actions.(3) The importance of H.C.G. in maintenance of early pregnancy has been widely accepted, reports have highlighted a potential role of H.C.G. in maintaining uterine quiescence in the third trimester. H.C.G. exerts a potent concentration dependent inhibitory effect on human myometrial contractions. ${ }^{(4)}$ The H.C.G. receptors in human myometrium are downregulated following the onset of labour, in both term and preterm deliveries. ${ }^{(3,4)}$ H.C.G. in vitro acts by a type of mechanism connected to gas that can activate the plasma membrane of adenylate cyclase, thereby reducing specific gap junctions of myometrial cells and eventually decreasing surface tension of intracellular calcium, thus keeping myometer in zero phase of labour and causing uterine relaxation.(5) The power of H.C.G. in suppression of preterm labour might be due to direct restrain of myometer responses by production of eicosanoids. H.C.G. induces the production of eicosanoids, that are similar to prostacyclines, that immediately causes loosening of myometer muscles.(6) Recent data suggests that H.C.G. might have a role as an endogenous tocolytic agent in normal pregnancy. A significant decrease in serum H.C.G. level was found 2-3 weeks before the spontaneous onset of labour. This might contribute to increasing the contractility in the uterine muscle and gradually initiating the onset of labour.(7)

Following I.M. injection, peak concentration of H.C.G. occurs about 6 hrs after a dose. It is distributed primarily to gonads. Blood concentration declines in a biphasic manner, with a half-life between about 6 and $11 \mathrm{hrs}$ and 23 to $38 \mathrm{hrs}$ respectively. About 10 to $12 \%$ of an IM dose is excreted in urine within 24 hours. ${ }^{(8)}$

H.C.G. is therefore being evaluated as an endogenous tocolytic drug in our study.

METHODS: This study was a prospective study conducted in the Department of Obstetrics \& Gynaecology at Kamla Raja Hospital, Gwalior, M.P., from August 2011 to September 2012. After taking approval from the ethical committee, G.R. Medical College, Gwalior (M.P.), 50 women with established preterm contractions and labour were included in the study. Inclusion criteria's were: 4 uterine contractions per 20 min or 8 contractions per hour, single live fetus, pregnancy less than 37 weeks, intact membranes, dilatation less than $3 \mathrm{~cm}$ and effacement less than $80 \%$. Exclusion criteria were: abnormal vaginal bleeding, ruptured membranes, uterine anomalies, diagnosed congenital anomaly in the fetus, maternal infections, chorioamnionitis, maternal heart disease, APH, diabetes, preeclampsia, eclampsia or gestational hypertension, fetal disorders like fetal distress, IUGR, Polyhydraminos etc.

Gestational age was determined by last menstrual period and first trimester ultrasound dating. Informed written consent was obtained from all the patients. Also demographic informations were noted. Bishop's score at the time of admission was noted.

All patients were admitted in labour room and Haemoglobin concentration, urinanalysis and microscopical examination, blood group and Rh typing, blood sugar were done for all of them. In order to speed up fetal lung maturation, two doses of Inj. Betamethasone 12mg, 24hrs apart was given to all patients. In order to prevent any streptococcal infection in neonates, $2 \mathrm{gm}$ of iv ampicillin was given stat followed by 6 hrly injections.

H.C.G. was given in a dose of 5000units intramuscular injection followed by a drip of 10,000 units in $500 \mathrm{ml}$ of dextrose $5 \%$, at the rate of 20 drops per minute. Half hourly assessment of uterine contractions, maternal vital signs, fetal heart rate monitoring was done. 


\section{ORIGINAL ARTICLE}

Patients were kept under observation $24 \mathrm{hrs}$ after cessation of uterine contractions and arrest of labour. Follow up was performed in antenatal clinics. At each visit blood pressure, pulse rate and fetal heart rate were recorded. Signs and symptoms of preterm labour were reviewed. At the time of delivery, neonatal weight and weeks of gestation were determined to calculate duration of prolongation of pregnancy.

Tocolysis was considered successful when contractions ceased and delivery was delayed by $48 \mathrm{hrs}$ giving time to the administered corticosteroids to accelerate fetal lung maturation.

STATISTICS: Statistical analysis as done using Microsoft Excel.

RESULTS: The mean maternal age in our study was $24.96 \pm 3.71$ yrs. Mean parity in our study was $0.92 \pm 1.12$ i.e. maximum patients enrolled in our study were nulliparous. Mean gestational age at the time of enrollment in our study was 31.22 wks. 8 out of 50 patients (16\%) had history of previous preterm deliveries. Most of the patients presented with the complains of pain, backache and white discharge PV (22 out of 50: 44\%). Most of the patients enrolled in our study had Bishop's score in the range of 5-8 at the time of admission.

After initiation of tocolytic treatment, time required for suppression of contractions was noted in all patients. Mean duration between initiation of treatment and suppression of contractions was $3.1 \pm 0.12 \mathrm{hrs}$.

Average rate of labour within 48 hours in our study was $8 \%$ i.e. in $8 \%$ of patients, HCG was not able to suppress preterm labour and delivery occurred within 48hrs of initiation of treatment. In $92 \%$ of patients tocolysis was successful and delivery occurred more than $48 \mathrm{hrs}$ after initiation of treatment.

Mean prolongation of pregnancy in our study was $31.4 \pm 17.06$ days. In $76 \%$ of the patients, pregnancy was prolonged by more than 21 days. Prolongation of pregnancy was greatest when the tocolytic treatment was initiated in women with gestational ages between 28-29wk 6 days $(40.75 \pm 17.4$ days). Prolongation of pregnancy was maximum in women with preterm contractions having Bishop's score in the range of 0-4 i.e. 38.1 days. Patients enrolled in our study did not suffer from any maternal/ neonatal side effects.

The mean birth weight of babies delivered by the patients included in our study was $2.35 \pm 0.62 \mathrm{kgs}$. Maximum babies weighed in the range of $1.5-2.5 \mathrm{kgs}(62 \%) .3$ out of 50 patients $(6 \%)$ delivered babies weighing less than $1.5 \mathrm{kgs}$.

DISCUSSION: Spontaneous preterm labour is responsible for more than half of preterm births.(9) Tocolytic drugs like prostaglandin synthesis inhibitors, beta adrenoreceptor agonists and calcium channel blockers have potentially serious side effects on mother and infant.(10)

In our study H.C.G. was found to be beneficial in suppression of preterm labour and prolongation of pregnancy with no maternal, fetal or neonatal side effects. Prolongation of pregnancy was maximum in women with gestational ages in the range of 28-29wk 6 days and in women having preterm contractions having Bishop's scores in the range of 0-4 at the time of admission, indicating that earlier we start the tocolytic treatment with H.C.G., better are the results. In 4 out of 50 patients HCG failed to suppress preterm labour and delivery occurred within $48 \mathrm{hrs}$ of initiation of treatment. Further studies need to be done to establish the role of H.C.G. as a tocolytic agent. 


\section{ORIGINAL ARTICLE}

Carlos et al, observed that H.C.G. may play a significant role in maintaining pregnancy well after first trimester.(3) Mechanism of action of H.C.G. in treatment of threatened abortion maybe reduction of resistance against arterial blood flow. $(5,11)$

Slattery et al, demonstrated that H.C.G. exerts a significant concentration dependent relaxant effect on human myometrial tissues in the third trimester of pregnancy. ${ }^{(4)}$

Kurtzman et al reported the role of H.C.G. in maintenance of early pregnancy and its role in the maintenance of the later stage of pregnancy, by directly and indirectly promoting uterine quiescence. As an endogenous tocolytic, H.C.G. maybe an ideal candidate for the therapy of preterm labour.(12)

Ali et al, observed the mean prolongation of 28.8 days in H.C.G. treated group versus 15 days in placebo treated group, which was statistically significant difference between the two groups (p value $<0.001$ ), thus concluding that it exhibits potent tocolysis with no fetal side effects, when compared to placebo.(13)

Ibtissam Youssif AL Saffar et al conducted a study, using H.C.G., on 57 women with preterm labour in Bhagdad, Iraq from April 2006 till November 2006 and concluded that H.C.G. exhibits potent tocolysis, thereby prolonging pregnancy durations in women with preterm labour, without causing any adverse maternal/neonatal side effects.(14)

Sakhavar $\mathrm{N}$ et al, in their clinical trial study concluded that H.C.G. \& Magnesium sulphate have similar tocolytic efficacy but since H.C.G. has no maternal \& fetal side effects, it is a good alternative drug in suppression of preterm labour.(15)

Lorzadeh $\mathrm{N}$ et al., in their study found that delivery was delayed for $48 \mathrm{hrs}$ in $90.3 \%$ of women receiving H.C.G. The mean birth weight in their study was $2334 \mathrm{gm}$, which is almost similar to that found in our study. Also no adverse maternal/neonatal side effects were observed by them.(16)

CONCLUSION: H.C.G. exhibits potent tocolysis with no maternal/neonatal side effects. Further studies need to be done to establish role of H.C.G. in suppression of preterm labour.

\section{REFERENCES:}

1. Cunningham FG, Gant NF, Leveno KJ, Glisterap LC. Williams Obstetrics. 22nd Ed, New York: McGraw- Hill; 2005. P: 856- 8.

2. Lockwood Ci. Calcium- channel blockers in the management of preterm labor. The Lancet, 1997 350 (9088), 1339-1340.

3. Carlo Ticconi, Emilio Piccione, Alessia Belmonte, Ch. V. Reo. HCG- A new kid on the block in prematurity prevention. Journal of Maternal-Fetal and Neonatal Medicine, Obstet Gynecol 2006; 19th: 11 November.

4. Slattery MM, Brennan C, O’Leary, MJ, Morrison JJ. Human chorionic gonadotropin inhibition of pregnant human myometrial contractility. Br J Obstet Gynecol 2001; 108: 704-8.

5. Reshef F, Lei ZM, Rao Chv, Pridham DD, et al. The presence of gonadotropin receptors in nonPregnant human uterus, human placenta, fetal membranes and deciduas. J Clin Endocrinol Metab, 1999 70, 421- 429.

6. Chegini M, Lei ZM, Rao CV, Hansel W. Cellular distribution and cycle phase dependency of gonadotropin and eicosanoid binding sites in bovine corpora lutea. Biol Repord 1991; 45: 50613. 


\section{ORIGINAL ARTICLE}

7. Edelstam G, Karlsson, C, Westgren M, Lowbeer C, Swahn ML. Human choriononic gonadotropin (hCG) during third trimester pregnancy. Scandivian Journal of Clinical and Laboratory Investigation, Volume 67, No. 5, 2007, pp. 519-525(7).

8. Kathleen Parfitt, BSc, RF Pharma S, Martinadale. The complete drug Reference, 32ed edition 1999; part 1: 1- 1539.

9. Goldenberg, MD. Robert, L. The management of Preterm Labor. Obstet Gynecol 2002; 100: 1020-37.

10. R.J. phillips, A.J. Tyson- Capper (nee pollard), J. Bailey S. C. Robson, and G. N. Europe- Finner. Regulation of Expression of the chorionic Gonadotropin/ Luteinizing Hormone Receptor Gene in the Human Myometrium: Involvement of Specificity Protein - 1 (Sp1), Sp3, Sp4, Sp-Like proteins, and Histone Deacety lases. J. Clin, Endocrinol, Metab, June 1, 2005; 90: 3479-90.

11. Toth P, Gimes G, Paulin F, Rao Ch V. HCG treatment in early gestation: its impact on uterine blood flow and pregnancy outcome [abstract]. Fertil Steril, 1998 70, s46.

12. Kurtzman JT, Spinnato JA, Goldsmith LJ, Zimmerman MJ, Klem M, Lei ZM, Rao CV. Human chorionic gonadotropin exhibits potent inhibition of preterm delivery in a small animal model. Am J Obstet Gynecol 1999; 181: 853-57.

13. Ali Farid Mohamed Ali, Baha Fateen, Ahmed Ezzet, Hoda Badawy, Asherf Ramaan, Alaa El-tobge. Treatment of preterm labour with humanchorionic gonadotropin: anewmodality. Obstetrics \& Gynaecology, Vol. 95, Issue 4, supplement 1, April 2000, Pages S61.

14. Ibtissam Yousif AL - Saffar, Hala Ibrahim Salih. Human chorionic gonadotropin in treatment of preterm labour. The Iraqi postgraduate medical journal. Vol. 9, No. 3, 2010.

15. Sakhavar N, Mirteimoori M, Teimoori B. Magnesium Sulfate versus HCG (Human Chorionic Gonadotropin) in Suppression of Preterm Labor. Shiraz E-Medical Journal Vol. 9, No. 3, July 2008.

16. Nahid Lorzadeh, Sirus Kazemirad, Mina Lorzadrh and Afsaneh Dehnori. A comparison of human chorionic gonadotropin with Magnesium Sulphate in inhibition of preterm labour. J Med Sci, 7(4): 640-644, 15th May, 2007.

\begin{tabular}{|c|c|c|}
\hline Age (yrs) & Number & Percentage \\
\hline$<20$ & 4 & $8 \%$ \\
\hline $20-25$ & 25 & $50 \%$ \\
\hline $26-30$ & 15 & $30 \%$ \\
\hline$>30$ & 6 & $12 \%$ \\
\hline
\end{tabular}

Table 1: Distribution of cases according to maternal age

\begin{tabular}{|c|c|c|}
\hline Parity & Number & Percentage \\
\hline Nullipara & 19 & $38 \%$ \\
\hline Para 1 & 14 & $28 \%$ \\
\hline Para 2 & 14 & $28 \%$ \\
\hline Para 3 & 1 & $2 \%$ \\
\hline Para > 4 & 2 & $4 \%$ \\
\hline \multicolumn{2}{|c|}{ Table 2: Distribution of cases according to parity }
\end{tabular}




\section{ORIGINAL ARTICLE}

\begin{tabular}{|c|c|c|}
\hline No. of previous preterm deliveries & Number & Percentage \\
\hline 1 & 6 & $12 \%$ \\
\hline 2 & 1 & $2 \%$ \\
\hline$>3$ & 1 & $2 \%$ \\
\hline Total & $\mathbf{8}$ & $\mathbf{1 6 \%}$ \\
\hline
\end{tabular}

Table 3: Distribution of cases according to any previous preterm deliveries

\begin{tabular}{|c|c|c|}
\hline Gestational age & Number & Percentage \\
\hline$<28 w k$ & 4 & $8 \%$ \\
\hline 28-29wk 6 days & 8 & $16 \%$ \\
\hline 30-31wk 6 days & 18 & $36 \%$ \\
\hline 32-33wk 6 days & 15 & $30 \%$ \\
\hline 34-37wk & 5 & $10 \%$ \\
\hline
\end{tabular}

Table 4: Distribution of cases according to gestational age

\begin{tabular}{|c|c|c|}
\hline Symptomatology & Number & Percentage \\
\hline Pain & 16 & $32 \%$ \\
\hline Pain + Backache & 12 & $24 \%$ \\
\hline Pain + Backache + Discharge & 22 & $44 \%$ \\
\hline
\end{tabular}

Table 5: Distribution of cases according to symptomatology

\begin{tabular}{|c|c|c|}
\hline Bishop's score & Number & Percentage \\
\hline $0-4$ & 20 & $40 \%$ \\
\hline $5-8$ & 21 & $42 \%$ \\
\hline $9-13$ & 9 & $18 \%$ \\
\hline
\end{tabular}

Table 6: Distribution of cases according to Bishop's score

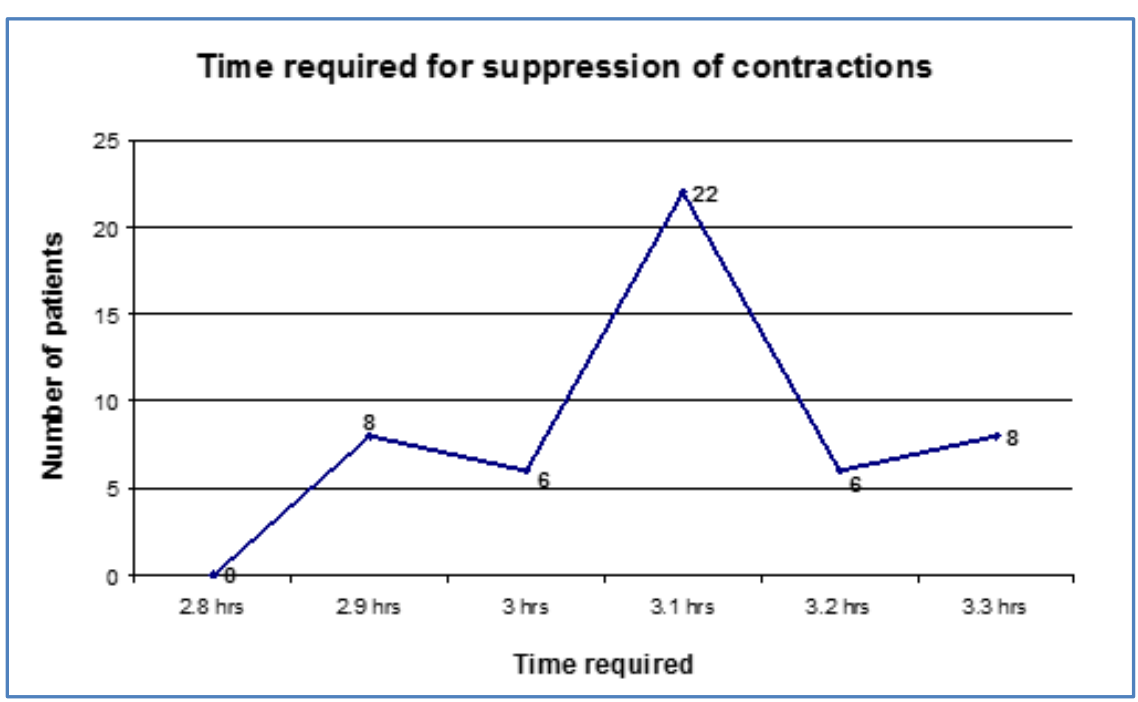




\section{ORIGINAL ARTICLE}

\begin{tabular}{|c|c|c|}
\hline No. of days Prolonged & Number & Percentage \\
\hline$<2$ & 4 & $8 \%$ \\
\hline 2 & 0 & $0 \%$ \\
\hline $3-6$ & 5 & $10 \%$ \\
\hline $7-13$ & 2 & $4 \%$ \\
\hline $14-20$ & 1 & $2 \%$ \\
\hline$>21$ & 38 & $76 \%$ \\
\hline \multicolumn{2}{|c|}{ Table 7: Distribution of cases according to no. of } \\
days prolonged after initiating treatment
\end{tabular}

\begin{tabular}{|c|c|}
\hline Gestational age & Mean days Prolonged ( $\mathbf{S D})$ \\
\hline$<28 w k$ & $38.75 \pm 26.53$ \\
\hline 28-29wk 6 days & $40.75 \pm 17.40$ \\
\hline 30-31wk 6 days & $34.16 \pm 14.13$ \\
\hline 32-33wk 6 days & $24.66 \pm 11.59$ \\
\hline 34-37wk & $20.8 \pm 24.79$ \\
\hline \multicolumn{2}{|c|}{ Table 8: No. of days prolonged wrt } \\
gestational age at the initiation of treatment
\end{tabular}
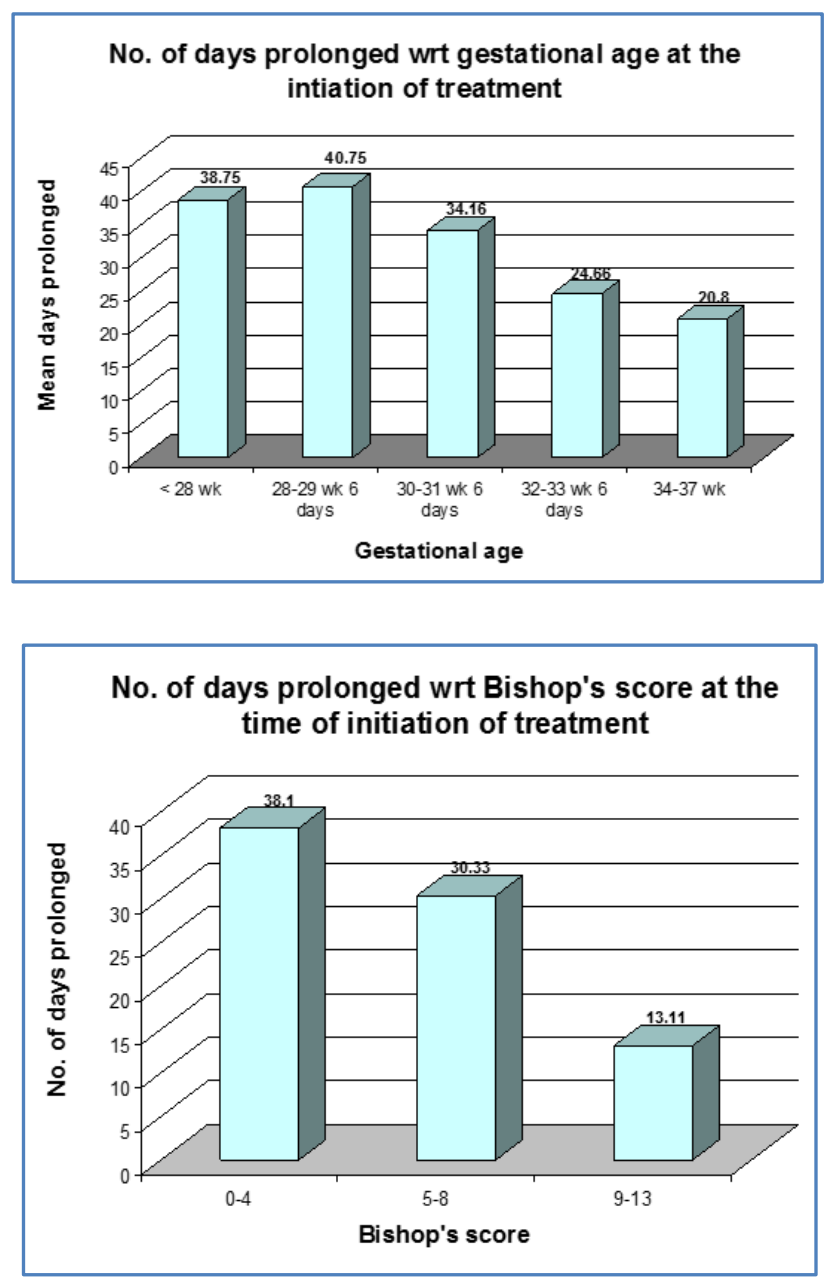


\section{ORIGINAL ARTICLE}

\begin{tabular}{|c|c|c|}
\hline Birth Weight (kg) & Number & Percentage \\
\hline$<1.5$ & 3 & $6 \%$ \\
\hline $1.5-2.5$ & 31 & $62 \%$ \\
\hline$>2.5$ & 16 & $32 \%$ \\
\hline$>3.5$ & 0 & $0 \%$ \\
\hline
\end{tabular}

Table 9: Showing birth weight of neonates born

\section{AUTHORS:}

1. Prakriti Goswami

2. Veena Agrawal

\section{PARTICULARS OF CONTRIBUTORS:}

1. Senior Resident, Department of Obstetrics and Gynaecology, G. R. M. C., Gwalior.

2. Ex-Professor \& HOD, Department of Obstetrics and Gynaecology, G. R. M. C., Gwalior.

FINANCIAL OR OTHER

COMPETING INTERESTS: None

\section{NAME ADDRESS EMAIL ID OF THE} CORRESPONDING AUTHOR:

Dr. Prakriti Goswami,

D-12, Tansen Road,

Gandhi Nagar, Gwalior-474002.

E-mail: goswami.prakriti@gmail.com

Date of Submission: 29/05/2015.

Date of Peer Review: 30/05/2015.

Date of Acceptance: 11/06/2015.

Date of Publishing: 16/06/2015. 